\title{
Ghosts of Gene Therapies Past: Lessons Learned From Jesse Gelsinger
}

\author{
Kevin Gorsky \\ News Reporter (HSI 2014-2015)
}

Prior to the complete sequencing of the human genome, the development of induced pluripotent stem cells and the fanfare surrounding Clustered Regularly Interspaced Short Palendromic Sequences (CRISPR) genetic editing systems, the biomedical sciences had an even bigger preeminent heavyweight: gene therapy. The development of techniques to sequence, clone, and directionally insert DNA in vitro collided at the inevitable junction of this revolutionary new science. However, bringing gene therapy applications to clinical trials revealed dangers and pitfalls that still hinder the field today. The tragic death of Jesse Gelsinger continues to highlight the multitude of hazards that have been linked to gene therapy for over 20 years, as well as the ethical considerations regarding the conflicts of interest present in clinical science.

Jesse Gelsinger did not die because he was sick. Jesse Gelsinger was born with Ornithine Transcobomylase (OTC) deficiency, a rare and often fatal $\mathrm{X}$-linked genetic metabolic disorder. However, Jesse did not inherit the disease from a mutated maternal allele. Rather, his mutated X chromosome occurred de novo, and because of the spontaneity of the mutation, did not affect the entirety of his liver cells. Jesse struggled through a childhood plagued by comas and neardeath spikes in his ammonia levels. However, with a strict low protein diet and a daily regimen of 32 pills, the young Mr. Gelsinger finally had his disease under control ${ }^{11}$. Jesse Gelsinger selflessly volunteered to be part of what he and his family believed was a low-risk trial, in hopes of someday helping children afflicted with OTC deficiency.

The clinical trial in question, the first of its kind, was conducted at the University of Pennsylvania (Penn) and headed by the renowned Dr. James Wilson. Dr. Wilson, in an effort to secure financial stability for the project, worked with Penn to further develop their technology transfer infrastructure, or as he puts it, to "establish a translational capability internal to the academic program at
Penn ${ }^{11}$." He also cofounded Genovo, a gene therapy-centric biotechnology company with vested financial interests in the outcome of his experimentation and clinical trials involving OTC deficiency ${ }^{4}$. These conflicts of interest, real or perceived, must be considered when analyzing the events surrounding the death of the young Jesse Gelsinger.

Dr. Wilson's OTC deficiency gene therapy trial involved the direct administration of an engineered attenuated adenovirus to the liver of enrolled subjects ${ }^{6}$. The adenoviral vector would bind to hepatocytes, inject its genome into the cells, and remain as a histone-associated, stable extra-chromosomal DNA aggregate in the nucleus ${ }^{6}$. Cellular transcription machinery could then transcribe the engineered OTC gene. Thus, infected hepatocytes would express a functional, though transient, OTC enzyme.

Seventeen patients had undergone treatment before Gelsinger, who was in the final cohort-the one receiving the highest titer of vector 6 . Jesse was administered the treatment on September 13th 1993, and experienced a drastically different response than previous trial subjects ${ }^{7}$. This response led to systemic inflammation and multi-organ failure, ultimately resulting in his death. This fulminate acute inflammatory response to vector was far more drastic than the adverse events observed in the other human candidates and the preclinical studies, most of which presented in fever and flu-like symptoms

Disregarding all other complicating factors, the death of a healthy adolescent in a phase 1 clinical trial would be sufficient controversy and cause to examine the underlying ethical factors and regulatory oversight involved in the experiment. Prior to enrolling patients in the trial, Dr. Wilson's team had consulted a panel of bioethicists and specialists regarding whether to conduct the trial in older, less affected young adults, or symptomatic, possibly terminal newborns ${ }^{2,8,11}$. The choice to reject the involvement of severely ill newborns was based on issues of informed consent, which would have to be given by guardians under enormously traumatic and coercive circumstances ${ }^{8}$. Protocol had been "meticulously" constructed, and it had received approval from the Food and Drug Administration 
(FDA) and the Institutional Review Board at the Hospital of the University of Pennsylvania ${ }^{3}$.

But the scenario was far from simple; several instances of foul play on Penn's behalf were dotted throughout the progression of the trial. Following Jesse's death and the suspension of the trial, questions were raised concerning non-compliance in many areas including adherence to eligibility and cessation criteria, completeness and content of the consent process, monitoring of subjects following vector dosing, timely notification to the FDA regarding animal toxicity data, and timeliness and accuracy of reports to the IRB and FDA $4,9,11$.

In an effort to sort out the lessons to be learned from Jesse Gelsinger's death, ethical concerns regarding gene therapy and clinical trials, importance of gene therapy over the past two decades, and appropriate relationship between academia and industry, I sat down with McGill University's Dr. Robert Murgita.

Dr. Murgita, whose accolades and experience read like a phonebook, is the founder and former director of the Sheldon Biotechnology Centre, former chairman and chief scientific officer at both IMMTEK and Atlantic Biopharmaceuticals INC., and has spent a decade as the chairman of the department of microbiology and immunology at McGill University. He has immense experience with technology transfer between academia and industry, and has been teaching a course for many years called the Business of Science, where he uses the story of Jesse Gelsinger as a case study.

The Gelsinger family and the University of Pennsylvania reached an out-of-court settlement over the negligence involved in Jesse's death. Dr. Wilson was publicly shamed and stripped of his ability to conduct clinical trials. As Dr. Murgita highlights, "The entire case was settled out of court in under four weeks. Because the case was settled in a matter of weeks, the files were frozen, and nobody knows the extent of the charges."

Dr. Murgita encourages his students to approach the case with an open mind and come to their own conclusions, but he did share some of his own inferences:

"One of the parties to be blame was the FDA. When Gelsinger was admitted to hospital prior to the procedure, his ammonia levels were high. They were higher than had been specified as the upper limit in the experimental protocol. Researchers at Penn then contacted the FDA and informed them that they would treat him to bring down his ammonia levels. That's a breach of the clinical trial rules right there. In the initial stage at least, the FDA is partially complicit." The trial team's adherence to the protocol has since been reevaluated by Wilson, who now admits that, "the protocol was not written in a way in which there was enough clarity to know when the ammonia had to be what [level], and that was a significant shortcoming ${ }^{9}$."

Dr. Murgita's opinion is that the implication of the FDA is what allowed the case to be settled as quickly as it was: "otherwise, no one has heard of cases like this being settled that fast. Penn didn't even have time to write their answers back to the lawsuit."

When I asked Dr. Murgita about the academic climate regarding gene therapy during the time of the clinical trial, he responded, "Very high. It's like other scientific waves, [gene therapy] was the next greatest thing. In fact Dr. Francis Collins of human genome project fame used gene therapy as one of his examples of why we needed to spend 3 billion to sequence the human genome: to help gene therapy advance." Understanding the hype and potential profit surrounding gene therapy and genetic technologies is important for appreciating the context of the Gelsinger case. Hundreds of millions of dollars from pharmaceutical corporations, biotech companies, and universities were funneled into gene therapy research during this time ${ }^{9,10}$. However, this incredible boom in research funding was not spurred out of a sudden coordinated generosity of "big pharma" to rid the world of rare orphan diseases, but rather due to the billions that stood to be made in gene therapy applications to cancer and degenerative disorders $3,4,9$.

How far has gene therapy come since the Gelsinger case sent reverberations through the field, shutting down labs and suspending research trials across the country? Dr. Murgita notes that "there are some successes today. Macular degenerative eye disease is one. Certain kinds of diseases appear to show some benefit, perhaps in some cancers." And of course he is correct, but that's not all. Severe Combined Immune Deficiency (SCID), famously known as the 'bubble-boy' disease, is another terrible genetic affliction that renders an individual's immune system completely ineffective ${ }^{1}$. Late $90^{\prime}$ 's gene therapy trials in SCID patients showed early success, but were quickly derailed by the development of retroviral-vector-induced-leukemia in a significant cohort of patients ${ }^{1}$. However, Donald Kohn, MD, from UCLA recently concluded following the October 
2009 NEJM publication of his research, that "more than 50 patients have been treated by gene therapy between trials in Italy, the UK and... the US in the past decade and a half. None have had complications from the gene transfer and most have successful immune reconstitution" ${ }^{\prime}$. Though some triumphs have been reported, the initial fanfare surrounding gene therapy has markedly dissipated. Though the Gelsinger case may have nucleated this downfall, the illusiveness of gene therapy applications continue to be characterized by the difficulty of the safe and stable introduction of target genes into patient DNA ${ }^{5}$.

Was the criticism leveled against him warranted? "Yeah, he made mistakes, as any scientist would do. I don't think he did anything malicious though. That runs counter to the conflict of interest charge leveled against him, because if something like this happens, you're finished."

Dr. Murgita can certainly relate to the circumstance. "I did the same thing with McGill in 1994. Since I was a post-doc I was studying a molecule that had potential therapeutic value and we started a company."

The gene therapy trials at Penn broach another pertinent question to the relationship between business and academia. Technology transfer and licensing fees are a huge source of revenue for universities such as Northwestern and Stanford. This may be an effective business model for an academic institution, but where is the line then drawn? "Of course you need to have protective devices, because it can be abused." In reference to McGill Dr. Murgita notes, "Professors all have contracts dictating that you can't do anything without the consent of the university over $20 \%$ of the time. Already there's oversight, you can't go running around doing what you want."

However, Murgita still thinks that technology transfer should play a significant role in sustaining a successful research oriented university. He is an advocate of the business model employed by large American institutions such as Stanford and Northwestern, whereby an entrepreneurial translational research environment is highly encouraged. Murgita: "There certainly needs to be guidelines against conflict of interest, but that should not stop entrepreneurial activity in universities. Further, universities will never have the resources that 'big pharma' have for developing drugs, and that's really not our role. We are discovery units. We are the initial source of discovery, and I don't believe we should be involved in the other end of development. Though clinical trials do go on in universities, the money to conduct these trials most often comes from some other source." At Stanford, one of the models of successful technology transfer, the office of technology licensing helps turn scientific progress into tangible products while returning income to the inventor and the university to support further research.

When money comes in from outside investors and mergers with biotechnology firms, financial incentives become part of the picture. Does this outside pressure to turn research into marketable compounds affect attention to patient safety? When asked Murgita replied, "I have a totally different perspective on this, maybe it's because I came from the states. I think we have a moral obligation to make research translational. My personal philosophy is that we should always be cognizant of the fact that we should be doing things that can be translated to the benefit of general society. That's what science ultimately is all about. It shouldn't be a matter of having outside pressure; the pressure should come from within towards translational applications."

As a final thought, Dr. Murgita reflected on the future of gene therapy applications. "The newest hottest thing is CRISPR. CRISPR was discovered in bacteria as a gene editing system to allow bacteria to destroy phages that infect them. Now everyone is using CRISPR, it's said to be the replacement for classical gene therapy, because it can knock in and knock out genes in a very effective way. Everyone's using CRISPR now and CRISPR kits are becoming prevalent." Does he consider this technology to represent the resurgence of gene therapy? "Absolutely. They claim it's much more effective. This technology doesn't need viral vectors. In the scientific journal Science and Nature it was the most written about topic in 2014."

Gene therapy has yet to live up to the promises associated with the technology from its inception, and perhaps never will. However, the scientific community cannot afford to forget Jesse Gelsinger, and the successes and missteps that have become synonymous with his story as well as the evolving history of gene therapy. The intersection between research and financial incentives are nowhere more evident than in his case, and as such must be evaluated in order to maximize progress while prioritizing patient safety. As Dr. Murgita summarized, "I think that with the proper guidelines university-industrial relationships can flourish. However, there's always the possibility of a conflict of interest. These conflicts must be identified and corrected immediately, and they can be, but you have to have the 


\section{HeAlTH SCIENCE INQUiRY}

\section{resources."}

\section{References}

1. Rozenblum R, Jang Y, Zimlichman E, Salzberg C, Tamblyn M, Buckeridge D, et al. A qualitative study of Canada's experience with the implementation of electronic health information technology. CMAJ. 2011 Mar 22;183(5):E281-8.

2. Cavazzana-Calvo M, Fischer A. Gene therapy for severe combined immunodeficiency: are we there yet? J Clin Invest. 2007;117:1456-65.

3. Deakin CT, Alexander IE, Kerridge I. Accepting Risk in Clinical Research: Is the Gene Therapy Field Becoming Too Risk-averse? Mol Ther. 2009;17(11):1842-48. doi:10.1038/mt.2009.223

4. Hayden EC. Gene therapy researcher warns stem-cell scientists not to repeat his field's mistakes. Nature doi:10.1038/news.2009.455

5. Jenks S. Gene Therapy Death - "Everyone Has to Share in the Guilt". J Natl Cancer Inst. 2000;92(2):98-100.

6. Lewis R (2014) SCID-X1 Gene Therapy, Take 2. PLOS Blog. http://blogs.plos. org/dnascience/2014/10/09/good-guy-virus-scid-x1-gene-therapy-take-2/

7. Raper SE, Yudkoff M, Chirmule N, Gao GP, Nunes F, Haskal ZJ, Furth EE, Propert KJ, Robinson MB, Magosin S, Simoes H, Speicher L, Hughes J, Tazelaar J, Wivel NA, Wilson JM, Batshaw ML. A pilot study of in vivo liver directed gene transfer with an adenoviral vector in partial ornithine transcarbamylase deficiency. Hum Gene Ther. 2002;13:163-175.

8. Raper SE, Chirmule N, Lee FS, Wivel NA, Bagg A, Gao GP, Wilson JM, Batshaw ML. Fatal systemic inflammatory response syndrome in a ornithine transcarbamylase deficient patient following adenoviral gene transfer. Mol Gen Metab. 2003;80:148-58.

9. Shalala D. Protecting research subjects-what must be done. N Engl J Med. 2000;343:808-10.

10. Wenner M. (2009) Gene therapy: An Interview with an Unfortunate Pioneer. Web: http://www.scientificamerican.com/article/gene-therapyan-interview/

11. Wilson JM. Medicine. A history lesson for stem cells. Science 2009;324(5928):727-728.

12. Wilson JM. Lessons learned from the gene therapy trial for ornithine transcarbamylase deficiency. Mol Gen Metab. 2009; 96: 151-57.

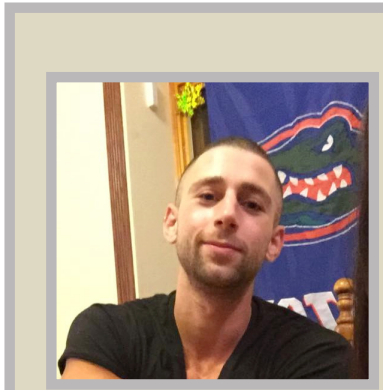

\section{Kevin Gorsky}

Kevin Gorsky is a medical student at McGill University with a BSc in microbiology and immunology. An avid athlete and amateur bodybuilder, Kevin also embraces outdoorsmanship and travel. Kevin's research acumen includes experiences in both fundamental and clinical research including HCV InRNA quantification and coronary artery bypass grafting (CABG) patency studies. Kevin is currently receiving training in rheumatology at Mt. Sinai Hospital in Toronto, where he is involved with quality improvement research. 